\title{
Evaluation of Abuse-Deterrent or Tamper-Resistant Opioid Formulations on Overall Health Care Expenditures in a State Medicaid Program
}

\author{
Shellie L. Keast, PharmD, PhD; Arthur Owora, MPH, CPH; \\ Nancy Nesser, PharmD, JD; and Kevin Farmer, PhD
}

\begin{abstract}
BACKGROUND: The development of abuse-deterrent opioid prescription medications is a priority at the national level. Pharmaceutical manufacturers have begun marketing new formulations of currently available opioids that meet higher abuse resistance standards. Little information is available regarding the impact of these formulations on overall health care expenditures.

OBJECTIVES: To (a) examine the relationship between health care expenditures and use of brand abuse-deterrent or tamper-resistant (ADTR) extended-release opioids versus standard dosage form (SDF) extendedrelease opioids in a state Medicaid population, and (b) determine whether this relationship was influenced by member-specific characteristics.

METHODS: The study is a cross-sectional review of Oklahoma Medicaid members (aged $\geq 21$ years) with at least 1 paid pharmacy claim for longacting opioids between September 2013 and August 2014. Members who were adherent to extended-release opioid products were classified into ADTR and SDF opioid groups. The relationship between health care expenditures (prescription, medical, and overall) and opioid groups was examined using multiple linear regression models. The impact of member-specific characteristics (age, sex, race, urban classifications, and various comorbidities) on this relationship was examined.
\end{abstract}

RESULTS: Prescription spending $(\$ 9,265,554)$ accounted for $35 \%$ of overall health care expenditures $(\$ 26,304,693)$ among 938 members during the 12-month reference period. Total prescription expenditures were higher among ADTR than SDF user groups, and the difference in median expenditures between these 2 groups was larger among members with more comorbidities, as measured by the Charlson Comorbidity Index score. Overall, ADTR users had higher median total health care and medical expenditures, and the difference in median expenditures was dependent on whether a member had comorbidities of addiction or not (higher expenditures were observed among members with comorbidities of addiction).

CONCLUSIONS: The abuse and misuse of medically prescribed opioid products is a growing health epidemic. A variety of attempts have been made to reduce the potential of abuse and misuse of these products, including changes to product formulations. The results of this study indicate that both prescription spending and physician and pharmacy spending combined may be increased with the use of these new products because of higher pricing. Study findings also suggest that the use of ADTR opioids among members with comorbidities of addiction may be related to slightly lower overall health care and medical expenditures than those among members without comorbidities of addiction. Further research is required to answer questions regarding the comparative effectiveness of existing opioid prescription formulations.

J Manag Care Spec Pharm. 2016;22(4):347-56

Copyright $\odot 2016$, Academy of Managed Care Pharmacy. All rights reserved.

\section{What is already known about this subject}

Patients with history of prescription opioid abuse incur health care costs at a higher level than patients without an abuse history. New abuse-deterrent opioid formulations are being manufactured to aid in reducing potential abuse of prescription opioids.

The new patented formulations are reimbursed at a higher rate than standard generic opioid formulations.

\section{What this study adds}

Prescription expenditures for users of abuse-deterrent or tamperresistant formulations are higher than those for users of standard dosage formulations.

Median medical expenditures for users of either formulation types were not found to be different.

In this study, use of advanced formulations did not result in lower total health care expenditures.
$\Lambda$ ccording to estimates from the 2013 National Survey on Drug Use and Health, 6.5 million people in the United States were current users of prescription drugs for nonmedical purposes, with 4.5 million of those using prescription pain relievers. ${ }^{1}$ The associated cost to the health care system for those who abuse prescription pain relievers has been shown to be higher than that for nonabusers. For example, based on administrative databases of medical and pharmacy claims from 16 self-insured employer health plans between 1988 to 2002, White et al. (2005) found that opioid prescription drug abusers incurred significantly higher mean annual health care expenditures than nonabusers $(\$ 15,884$ vs. $\$ 1,830 ; P<0.01){ }^{2}$ In this study, the prevalence of opioid abusers was found to be 8 per $10,000 .^{2}$ Another study conducted in a Medicaid population by McAdam-Marx et al. (2010) confirmed these findings, noting that mean total 1-year expenditures for those categorized as drug-abusing patients were an average of \$5,874 more than those for patients categorized as nonabusers. ${ }^{3}$ Additionally, costs and abuse trends have been shown to differ based on various patient-specific features including demographics, social status, and geographic location. ${ }^{2-5}$ Poverty and unemployment rates tend to have a positive correlation with rates of 
prescription opioid abuse. ${ }^{4}$ In addition, those who abuse opioids tend to have a higher prevalence of opioid-related comorbidities. $^{2,3,5}$ The high prevalence and expenditures related to misuse of prescription opioids underscore the need for preventive interventions at both the local and national levels, especially among the poorest patients, such as those served by the Medicaid program.

In 2011, the Office of National Drug Control Policy issued a paper titled "Epidemic: Responding to America's Prescription Drug Abuse Crisis." Among the action items included in the paper were 2 items related to abuse-deterrent formulations of opioid products. The first item directs the U.S. Food and Drug Administration (FDA) to provide guidance to pharmaceutical manufacturers on the development of abuse-deterrent formulations and postmarketing assessment of the performance of those products. The second item directs the National Institute for Drug Abuse and the Department of Health and Human Services to "expedite research on the development of pain medications with no abuse potential and abuse-deterrent formulations" by means of grants, partnerships, and priority review by the FDA. ${ }^{6}$

The FDA released draft guidance for abuse-deterrent formulas for pharmaceutical manufacturers in January 2013, which was finalized in April 2015.7 The guidance document included nonbinding recommendations for both premarketing and postmarketing studies. Under these guidelines, it was appropriate to include data from each of 3 premarketing study categories: (a) "laboratory-based in vitro manipulation and extraction studies (category 1); (b) pharmacokinetic studies (category 2); and (c) clinical abuse potential studies (category 3)."' Allowances were made for additional postmarketing studies (category 4) to be analyzed to determine the impact of an abuse-deterrent formulation on actual abuse. The guidance document also lists 7 current types of abuse-deterrent formulations, including physical/chemical barriers that limit drug release after manipulation, agonist/antagonist combinations where the antagonist is released upon manipulation, and delivery systems such as depot injections or implants. ${ }^{7}$

New labeling included statements about the premarketing studies listed above. For example, in April 2010 the FDA approved a new formulation of extended-release oxycodone $\mathrm{HCl}$ (OxyContin) designed to deter abuse associated with crushing the tablets. ${ }^{8}$ Labeling reflects the fact that category 1 and category 2 studies have shown abuse deterrence for the nasal route of administration. In October 2014, a long-acting capsule containing morphine sulfate plus naltrexone (Embeda) was approved with abuse-deterrent labeling and has been shown to reduce both oral and nasal abuse after the tablets have been crushed (categories 1 and 2). ${ }^{9}$ In November 2014 extended-release hydrocodone bitartrate (Hysingla ER) was approved and is expected to reduce abuse when the tablets are chewed and swallowed or when crushed and snorted or injected (categories 1 and 2). ${ }^{10}$
Extended-release hydromorphone (Exalgo) was released in 2010. Extended-release hydromorphone is formulated with the osmotic controlled-release oral drug delivery system to release drug at a controlled rate. It was hoped that the formulation would make it difficult to extract the hydromorphone by chewing, crushing, or dissolving the tablets. ${ }^{11}$ Extended-release hydromorphone was approved and released prior to both the draft and the final guidance, and does not carry abuse-deterrent labeling at this time. In December 2011, a revised formulation of extended-release oxymorphone $\mathrm{HCl}$ (Opana ER) was approved. Although it does not currently include abuse-deterrent labeling, it was designed to deter abuse through resistance to physical and chemical manipulation. ${ }^{12}$ Finally, in January 2015 the FDA approved a new formulation of extended-release hydrocodone bitartrate (Zohydro ER) with BeadTek, a technology designed to form a viscous gel when crushed and dissolved in liquids. ${ }^{13}$

There have been some early attempts to quantify the use of these newer formulations in terms of their increased costs and decreased abuse potential compared with older or generically available alternatives. ${ }^{14-23}$ Rossiter et al. (2014) compared the new formulation for extended-release oxycodone with the previous formulation and determined that a relative reduction in diagnosis of opioid abuse was present for the newer formulation. ${ }^{14}$ Additionally, the study determined that annual medical costs savings of $\$ 430$ million were associated with the newer formulation. ${ }^{14}$ In a report by Winegarden (2015), the net economic benefit for the new formulations was estimated to be between $\$ 1,757$ and $\$ 4,033$ per opioid patient. ${ }^{23}$ The majority of the research so far (largely centered on extended-release oxycodone) has indicated that the new formulations reduce abuse potential. ${ }^{16-22}$ In their research, Cicero and Ellis (2015) noted that although there was a decline in abuse of extendedrelease oxycodone after the release of the new formulation, this decline leveled off and abuse of the new formulation persisted. ${ }^{15}$ Abuse-deterrent technology holds great promise in the fight against prescription drug abuse, but it is important to remember that even products with abuse-deterrent properties can still be abused by the intended oral route of administration. $^{7}$ As the state Medicaid administrator, the Oklahoma Health Care Authority has taken numerous steps to curb abuse among the individuals served by the program, including preferential treatment for the abuse-deterrent formulations over similar non-abuse-deterrent formulations. ${ }^{24}$

The concept for this study predates both the draft and final versions of the FDA guidance for abuse-deterrent evaluation and labeling. ${ }^{.}$The products included in this study are reformulated extended-release oxycodone $\mathrm{HCl}$, reformulated extended-release oxymorphone $\mathrm{HCl}$, and extended-release hydromorphone. At the time the study was commenced, both extended-release oxymorphone $\mathrm{HCl}$ and extended-release hydromorphone were thought to have abuse-deterrent potential and thus included. Although the FDA uses the term 


\begin{tabular}{l|c}
\hline \multicolumn{1}{c}{ TABLE 1 } & Included Opioid Products \\
\hline Generic Name & Brand Name \\
\hline Hydromorphone & Exalgo \\
\hline Morphine & MS Contin \\
\hline Oxycodone & Oxycontin \\
\hline Oxymorphone & Opana ER \\
\hline ER=extended release. & \\
\hline
\end{tabular}

"tamper resistant" to describe packaging of products, the term is used here to distinguish products that may have some deterrent properties despite the lack of FDA-approved abusedeterrent labeling.

The objectives of this study were (a) to characterize the relationship between overall health care expenditures and use of brand-name abuse-deterrent or tamper-resistant (ADTR) extended-release opioids compared with similar standard dosage forms (SDFs) that are currently available as generic products and (b) to examine the influence of Medicaid member characteristics on this relationship. Characteristics examined included age, sex, race, urban classification, Charlson Comorbidity Index score, opioid dependence, and comorbidities of addiction.

\section{Methods}

\section{Study Design Overview}

Cross-sectional analyses were conducted using retrospective administrative claims data from the Oklahoma Health Care Authority's pharmacy and medical Medicaid paid claims database to compare the expenditures associated with use of ADTR opioid products with SDF alternatives within the Oklahoma Medicaid program. The Oklahoma Health Care Authority is the single state agency designated to administer the Medicaid program in Oklahoma. This study was approved by the University of Oklahoma Institutional Review Board and the Oklahoma Health Care Authority.

\section{Data Source}

This research utilized data from pharmacy and medical paid claims maintained by Pharmacy Management Consultants, the pharmacy benefit manager for Oklahoma Health Care Authority, in a secure server environment. Each pharmacy claim consisted of a single observation and contained information regarding medication, amount reimbursed, dispensed quantity, number of expected therapy days, dispense date, and prescriber. Medical claims included outpatient physician and hospital claims, inpatient hospital claims, and other billable services not related to pharmacy. The medical claims contained treatment and diagnostic codes, service dates, and reimbursement amounts. Once all claims were linked via the unique patient identifier, personally identifiable elements were removed prior to data analyses.

\section{TABLE 2 Products Included in Groups}

\begin{tabular}{l|c}
\hline Groups & Brand-Name Products \\
\hline Branded abuse-deterrent opioid & Oxycontin, Opana ER, Exalgo \\
\hline Standard dosage form & MS Contin, Oxymorphone ER \\
\hline ER=extended release. &
\end{tabular}

\section{Data Inclusion and Exclusion Criteria}

The included population consisted of Oklahoma Medicaid members who were continuously eligible for Medicaid only (no Medicare eligibility) from March 2013 through August 2014 (18 months); were aged at least 21 years at the start of the review period; and had at least 1 paid pharmacy claim for the following long-acting oral opioid products during March 2013: extended-release oxymorphone, extended-release oxycodone, extended-release hydromorphone, and extended-release morphine sulfate (Table 1). March 2013 was selected because of the start of a prior authorization for generic extended-release oxymorphone. A total of 18 months was used to classify patients in groups based on product use and adherence. The final 12 months of the period (September 2013 through August 2014) were used to determine annual expenditures. A chronic pain medication user was defined as an individual whose proportion of days covered for long-acting opioid products was at least $60 \%$ of the entire review period. Studies of adherence may use a cutoff of $80 \%$ to indicate adherence ${ }^{25,26}$; however, because adherence was not a focus of this research, $60 \%$ was used to determine if a member had possession of a product for a majority of the studied time period. Finally, to be classified into the study groups, the member must have met the following criteria (see Table 2 for group descriptions):

1. To be included in the ADTR group, the member's proportion of days covered must have been 0.60 or greater for an ADTR product during the review period.

2. To be included in the SDF group, the member's proportion of days covered must have been 0.60 or greater for a SDF product during the review period.

Members were excluded from the study if they met criteria for inclusion in both ADTR and SDF groups (Figure 1).

\section{Outcome Ascertainment}

The dependent variables were based on overall health care expenditures including (a) annual prescription expenditures, (b) annual medical expenditures, and (c) overall annual health care expenditures.

\section{Explanatory Variables}

The covariates examined in this study were based on Andersen and Newman's (2005) model of health care determinants. ${ }^{27}$ They included age, sex, race, and urban/rural designation. The 


\section{FIGURE 1 Exclusion and Inclusion Flow Diagram}

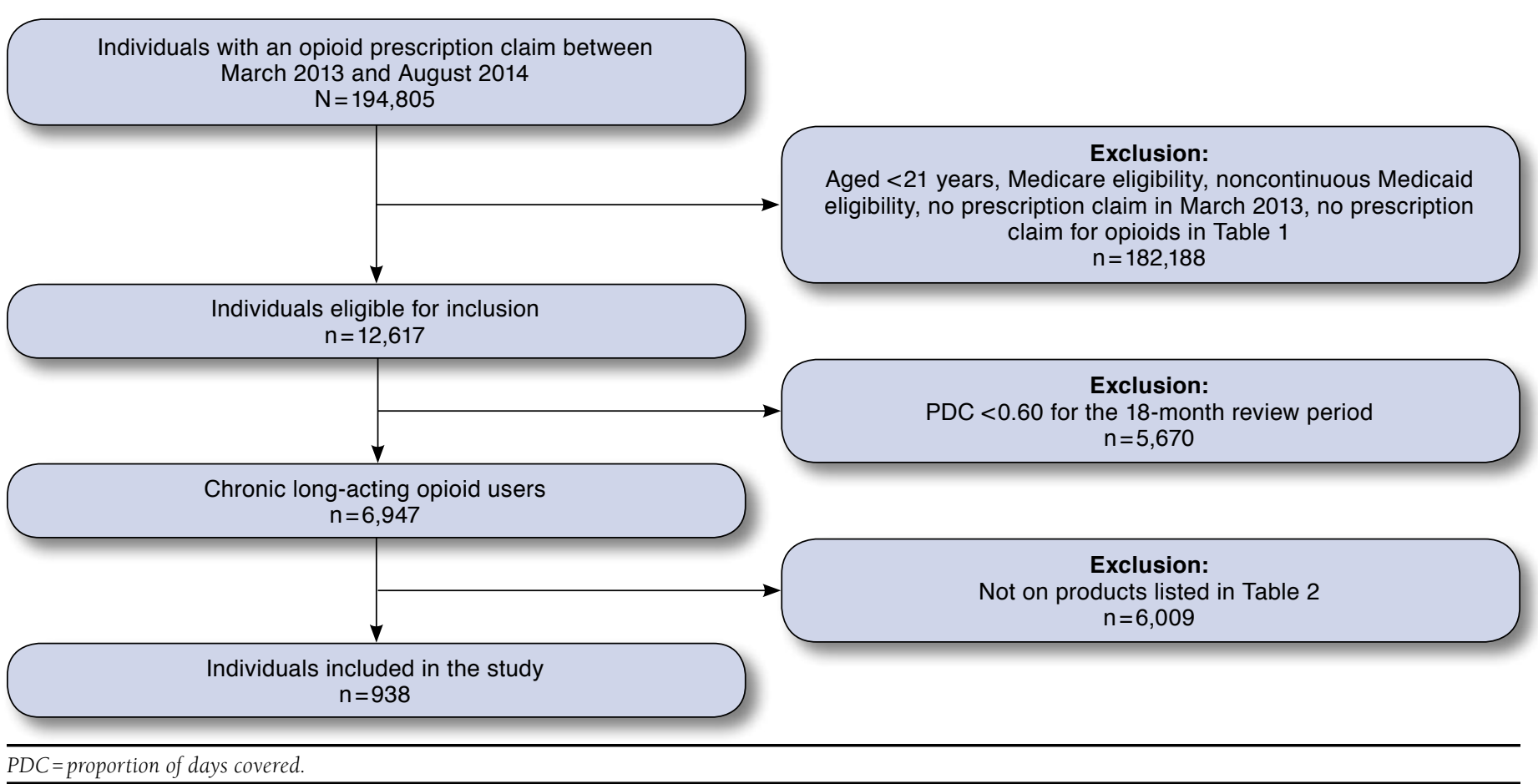

individual's illness level was taken into consideration by use of the Charlson Comorbidity Index score. ${ }^{28,29}$ Additionally, the comorbidities often associated with addiction were counted using International Classification of Diseases, Ninth Revision, Clinical Modification (ICD-9-CM) codes. The included comorbidities were based on those found to be associated with opioid abuse $^{2}$ and included human immunodeficiency virus/acquired immunodeficiency syndrome; hepatitis A, B, and C; substance abuse; skin infections; gastrointestinal bleeding; liver disease; pancreatitis; sexually transmitted diseases; burns; motor vehicle traffic accidents; poisoning; trauma; and mental disorders (see Appendix for complete list and ICD-9-CM codes, available in online article). Individuals were also designated as having a

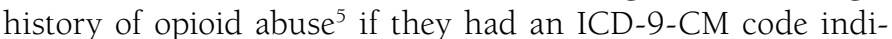
cating opioid dependence or abuse (304.0x, 304.7x, 305.5x, 965.0x [excluding 965.01]).

\section{Statistical Analysis}

Descriptive statistics were used to summarize the distribution of Medicaid members' demographic and health care expenditures by opioid use classification. Multivariable linear regression models were used to examine the relationship between overall health care expenditures (overall health care expenditures, medical expenditures, and total prescription expenditures) and type of opioids used by Medicaid members during a 12-month period between 2013 and 2014, and whether this relationship was modified by member characteristics such as age, sex, race, residence, resource use (number of prescribers, prescriptions, and emergency department utilization), Charlson Comorbidity Index scores, opioid dependence, and comorbidities of addiction.

Cost outcomes (overall health care, medical, and prescription expenditures) were log transformed to meet linear regression modeling assumptions. There was no evidence of potential outliers or multicollinearity among independent variables examined. Dummy coding was used for sex, race/ethnicity, residence, Charlson Comorbidity Index scores, opioid dependence, comorbidities of addiction, and emergency department visits to facilitate appropriate comparisons across factor levels.

Full models including all the selected covariates and pairwise interaction terms were examined for overall health care, medical, and prescription expenditure outcome models. Expenditure differences between Medicaid members defined by opioid classification were examined at levels of identified moderating factors: Charlson Comorbidity Index scores and comorbidities of addiction (interaction terms: $P<0.05$ ). In the absence of significant interaction terms, potential confounding effects were evaluated. A variable was considered a confounder if its inclusion in or deletion from the model resulted in more than a $10 \%$ difference in the regression parameter of a covariate association of interest. 
All final linear regression models examined showed good fit to data based on $F$ test results $(P<0.05)$. The significance of each term (interaction and main effects) in the final regression models was based on t-tests (null hypothesis: regression parameter estimate equal to zero). Ordinary least squares estimation procedures were used to estimate the regression parameters. Statistical significance tests were adjusted for multiple comparisons using the Tukey adjustment for comparisons across categorical factor levels, and the significance of tests was determined at an alpha of 0.05. All data analyses were conducted using SAS software, version 9.3 of the SAS System for Windows (SAS Institute, Cary, NC).

\section{Results}

A total of 12,617 Oklahoma Medicaid-eligible members met initial inclusion criteria for the study. After applying chronic long-acting opioid criteria, 6,947 members remained. Of these remaining members, only $938(0.5 \%)$ were using products listed in Table 2 and were considered eligible for this study.

Descriptive statistics for study participants' demographic characteristics, health care expenditures, and resource use by opioid classification are summarized in Table 3. Bivariate comparisons showed that the annual median total health care expenditures were $\$ 9,936$ higher among ADTR users compared with SDF users $(P<0.01$; Table 3$)$. Annual median total medical expenditures were not significantly different between the ADTR and SDF groups. Annual median total prescription expenditures were $\$ 8,313$ higher in the ADTR group compared with the SDF group $(P<0.01)$. Annual median prescription expenditures for opioid-based prescriptions were $\$ 8,390$ higher in the ADTR group compared with the SDF group $(P<0.01)$. Overall, prescription expenditures $(\$ 9,265,554)$ accounted for $35 \%$ of combined physician and pharmacy health care expenditures $(\$ 26,304,693)$ among 938 members during the 12-month reference period. Study members' per member per month prescription expenditures were higher than the average per member per month costs for Oklahoma Medicaid members who utilized pharmacy services in state fiscal year 2014 (\$823 vs. \$185, respectively).

\section{Total Health Care Expenditures}

Multivariable linear regression results showed that a significant proportion (44\%) of variation in overall health care expenditures $\left(R^{2}=0.44 ; P<0.01\right)$ was explained by investigated participant characteristics and resource use. For both the ADTR and SDF users, the median total health care expenditures differed depending on whether they had comorbidities of addiction and their Charlson Comorbidity Index scores (i.e., interaction terms between opioid classification and Charlson Comorbidity Index scores/comorbidities of addiction; $P<0.01)$. Specifically, the median total health care expenditures were higher among members with comorbidities of addiction and high Charlson
Comorbidity Index scores than among members with no comorbidities of addiction and lower Charlson Comorbidity Index scores, holding all other factors constant (Table 5). Having more prescriptions $(P<0.01)$ and a higher number of emergency department visits $(P<0.01)$ was significantly associated with higher median overall health care expenditures after controlling for differences in the distribution of other participant characteristics and resource use (Table 4).

\section{Total Medical Expenditures}

A significant proportion (31\%) of variation in medical expenditures was explained by investigated participant characteristics and resource use $\left(R^{2}=0.31 ; P<0.01\right)$. Similar to the results observed for overall health care expenditures, the median total medical expenditures among both ADTR and SDF users differed depending on whether a member had comorbidities of addiction (i.e., interaction terms between opioid classification and comorbidities of addiction; $P=0.04$ ). Among SDF users, the total medical expenditures were higher among members with comorbidities of addiction than among members without comorbidities of addiction (Table 5). Conversely, among ADTR users, total medical expenditures were lower among members with comorbidities of addiction than among members without comorbidities of addiction; however, the difference in median expenditures was not statistically significant $(P>0.05)$. Median total medical expenditures did not seem to vary depending on patient Charlson Comorbidity Index scores (i.e., Charlson Comorbidity Index scores did not modify the association between medical expenditures and the type of opioid prescription a member used, whether ADTR or SDF). Having more prescriptions $(P<0.01)$, more prescribers $(P<0.01)$, and more emergency department visits $(P<0.01)$ was significantly associated with higher median medical expenditures after controlling for differences in the distribution of other participant characteristics and resource use (Table 4).

\section{Total Prescription Expenditures}

A significant proportion (42\%) of variation in prescription expenditures was explained by investigated participant characteristics and resource use $\left(R^{2}=0.42 ; P<0.01\right)$. Median total prescription expenditures among ADTR versus SDF opioid use differed depending on a member's Charlson Comorbidity Index score (i.e., interaction terms between opioid classification and Charlson Comorbidity Index score; $P<0.01$ ). Total prescription expenditures were higher among ADTR than SDF users and rose with increasing Charlson Comorbidity Index score (Table 5). As expected, having more prescriptions $(P<0.01)$ was significantly associated with higher median prescription expenditures after controlling for differences in the distribution of other participant characteristics and resource use (Table 4). 


\section{Evaluation of Abuse-Deterrent or Tamper-Resistant Opioid Formulations on Overall Health Care Expenditures in a State Medicaid Program}

TABLE 3 Descriptive Summary of Oklahoma Medicaid Member Demographics, Health Care Expenditures, and Resource Use by Opioid Classification for September 2013 through August 2014

\begin{tabular}{|c|c|c|c|c|c|}
\hline \multirow{2}{*}{$\begin{array}{l}\text { Characteristics } \\
\text { Demographics }\end{array}$} & \multicolumn{2}{|c|}{$\begin{array}{c}\text { Standard Dosage Form } \\
(\mathrm{n}=541)\end{array}$} & \multicolumn{2}{|c|}{$\begin{array}{c}\text { Abuse-Deterrent Tamper-Resistant } \\
(\mathrm{n}=397)\end{array}$} & \multirow[t]{2}{*}{$P$ Value } \\
\hline & & & & & \\
\hline Mean (SD) age, years ${ }^{\mathrm{a}}$ & 49 & (9) & 50 & $(10)$ & 0.27 \\
\hline Male, $\mathrm{n}(\%)^{\mathrm{b}}$ & 196 & $(36)$ & 151 & $(38)$ & 0.57 \\
\hline \multicolumn{6}{|l|}{ Race, $\mathrm{n}(\%)^{\mathrm{b}}$} \\
\hline Caucasian & 461 & $(85)$ & 311 & $(78)$ & 0.03 \\
\hline African American & 41 & (8) & 48 & $(12)$ & \\
\hline Asian & 38 & $(7)$ & 37 & (9) & \\
\hline Other (excluded from analysis) & 1 & $(<1)$ & 1 & $(<1)$ & \\
\hline \multicolumn{6}{|l|}{ Urban, n $(\%)^{\mathrm{b}}$} \\
\hline Metropolitan & 325 & $(60)$ & 244 & $(61)$ & 0.80 \\
\hline Micropolitan & 137 & $(25)$ & 95 & $(24)$ & \\
\hline Rural & 78 & $(14)$ & 58 & $(15)$ & \\
\hline Missing (excluded from analysis) & 1 & $(<1)$ & & & \\
\hline Charlson Comorbidity Index score, $\mathrm{n}(\%)^{\mathrm{b}}$ & & & & & $<0.01$ \\
\hline 0 & 278 & $(51)$ & 159 & $(40)$ & \\
\hline 1 & 128 & $(24)$ & 110 & $(28)$ & \\
\hline 2 & 49 & (9) & 60 & $(15)$ & \\
\hline 3 & 86 & (16) & 68 & $(17)$ & \\
\hline Opioid dependence, $\mathrm{n}(\%)^{\mathrm{b}}$ & & & & & $<0.01$ \\
\hline No & 473 & $(87)$ & 370 & $(93)$ & \\
\hline Yes & 68 & $(13)$ & 27 & $(7)$ & \\
\hline Comorbidities of addiction, $\mathrm{n}(\%)^{\mathrm{b}}$ & & & & & 0.38 \\
\hline No & 122 & $(23)$ & 80 & $(20)$ & \\
\hline Yes & 419 & $(77)$ & 317 & $(80)$ & \\
\hline Median (IQR) PDCc & 0.93 & $(0.15)$ & 0.97 & $(0.05)$ & $<0.01$ \\
\hline \multicolumn{6}{|c|}{ Median (IQR) 12-month summary of expenditures per member, $\$$} \\
\hline Rx expenditures ${ }^{\mathrm{b}}$ & 3,854 & $(5,097)$ & 12,167 & $(10,745)$ & $<0.01$ \\
\hline Opioid Rx expenditures ${ }^{b}$ & 1,532 & $(1,747)$ & 9,922 & $(7,138)$ & $<0.01$ \\
\hline Medical expenditures $^{b}$ & 9,306 & $(17,187)$ & 10,015 & $(19,622)$ & 0.38 \\
\hline Healthcare expenditures ${ }^{b}$ & 15,043 & $(22,996)$ & 24,979 & $(34,971)$ & $<0.01$ \\
\hline \multicolumn{6}{|c|}{ Median (IQR) 12-month summary of resource use per member } \\
\hline Number of Rx prescribers ${ }^{\mathrm{b}}$ & 26 & $(14)$ & 25 & $(17)$ & 0.87 \\
\hline Number of opioid prescribers ${ }^{b}$ & 13 & $(1)$ & 13 & $(2)$ & 0.02 \\
\hline Number of $\mathrm{Rx}^{\mathrm{b}}$ & 68 & $(21)$ & 67 & $(21)$ & 0.99 \\
\hline Number of narcotic $\mathrm{Rx}^{\mathrm{b}}$ & 26 & $(5)$ & 27 & (3) & $<0.01$ \\
\hline Number of ED visits ${ }^{\mathrm{b}}$ & 1 & $(0)$ & 1 & $(0)$ & 0.52 \\
\hline \multicolumn{6}{|l|}{ ED visit categories, $\mathrm{n}(\%)^{\mathrm{c}}$} \\
\hline 1 & 464 & $(86)$ & 346 & $(87)$ & 0.54 \\
\hline $2+$ & 77 & $(14)$ & 51 & (13) & \\
\hline \multicolumn{6}{|c|}{$\begin{array}{l}\text { aIndependent sample t-test. } \\
\text { bChi-square test of independence. } \\
\text { 'Wilcoxon independent } 2 \text {-sample test. } \\
E D=\text { emergency department; } I Q R=\text { interquartile range; } P D C=\text { proportion of days covered; } R x=\text { prescription; } S D=\text { standard deviation. }\end{array}$} \\
\hline
\end{tabular}

\section{Discussion}

The misuse and abuse of prescription opioid products is becoming a national health problem equal to that of illicit street drugs. State Medicaid agencies and third-party insurers have attempted to thwart misuse and abuse by programmatic means such as lock-in programs, quantity limits, prior authorization requirements, and step therapy. ${ }^{24}$ Pharmaceutical manufacturers have responded with the development of ADTR formulations of existing opioid products. Because these newly formulated products are patent protected, their cost is considerably higher than that of the generic alternatives to the original opioid product. For payers like state Medicaid agencies, the question then becomes whether there are any tangible health outcome benefits or cost savings associated with paying for 


\section{Evaluation of Abuse-Deterrent or Tamper-Resistant Opioid Formulations on Overall Health Care Expenditures in a State Medicaid Program}

TABLE 4 Linear Regression Results of Health Care Expenditures (Log Scale) by Medicaid Member Characteristics Derived from the Multivariable Linear Regression Models ( $N=938$ )

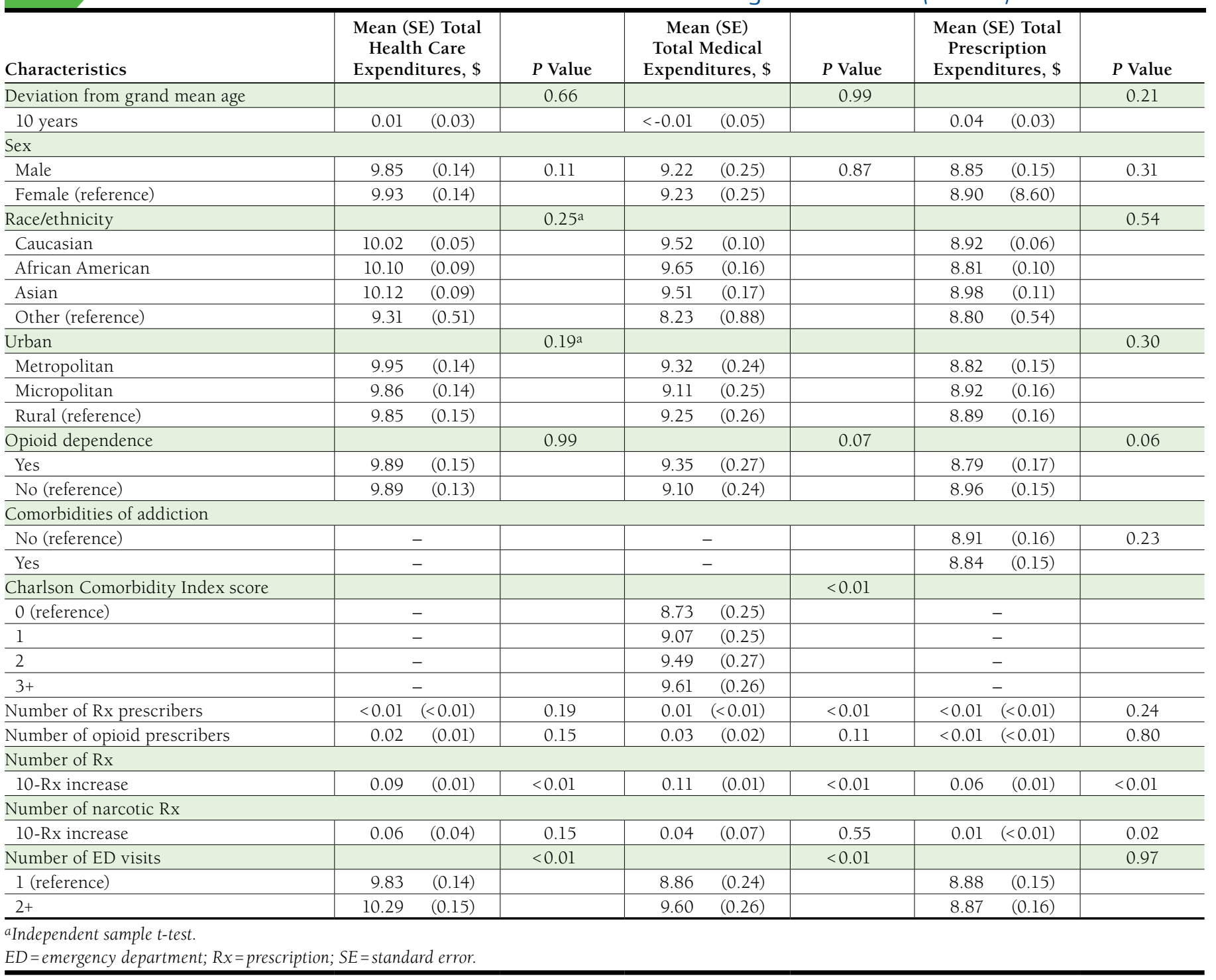

these specific products. Does the additional cost of ADTR formulations lead to fewer emergency department visits (presumably because of more appropriate use or dosing) or cost savings in medical expenditures?

Overall total health care expenditures were significantly higher among ADTR than SDF users even within strata of Charlson Comorbidity Index scores and comorbidities of addiction, holding other factors constant (Table 5). Median total health care expenditures were higher in individuals with higher Charlson Comorbidity Index scores and comorbidities of addiction, which should be expected because these individuals would be considered sicker from a general health and substance abuse addiction standpoint. Each additional score in the Charlson Comorbidity Index resulted in a higher expected median expenditure in both groups. In the case of comorbidities of addiction, the expected median expenditures were significantly higher in the ADTR group than in the SDF group. Examination of separate medical and pharmacy/prescription expenditures indicated the difference in total health care expenditures was essentially driven by higher spending for prescription drugs, primarily opioid products. Median medical expenditures were not found to be significantly different between the 2 groups. The number of emergency department visits during the study period was not significantly different 
Evaluation of Abuse-Deterrent or Tamper-Resistant Opioid Formulations

on Overall Health Care Expenditures in a State Medicaid Program

\begin{tabular}{|c|c|c|c|c|c|c|c|c|c|}
\hline \multirow{3}{*}{$\begin{array}{l}\text { TABLE } 5 \\
\text { Characteristics }\end{array}$} & \multicolumn{9}{|c|}{$\begin{array}{l}\text { Linear Regression Results of Health Care Expenditures (Log Scale) by Opioid Classification and } \\
\text { Medicaid Member Characteristics Derived from the Multivariable Linear Regression Models (N=938) }\end{array}$} \\
\hline & \multicolumn{3}{|c|}{$\begin{array}{c}\text { Mean (SE) Total Health Care } \\
\text { Expenditures, \$ }\end{array}$} & \multicolumn{3}{|c|}{$\begin{array}{l}\text { Mean (SE) Total Medical } \\
\text { Expenditures, } \$\end{array}$} & \multicolumn{3}{|c|}{$\begin{array}{c}\text { Mean (SE) Total Prescription } \\
\text { Expenditures, \$ }\end{array}$} \\
\hline & $\begin{array}{c}\text { Generic } \\
\text { Alternative } \\
(\mathrm{n}=541)\end{array}$ & $\begin{array}{l}\text { Abuse } \\
\text { Deterrent } \\
(\mathrm{n}=397)\end{array}$ & $P$ Value & $\begin{array}{c}\text { Generic } \\
\text { Alternative } \\
(\mathrm{n}=541)\end{array}$ & $\begin{array}{c}\text { Abuse } \\
\text { Deterrent } \\
(\mathrm{n}=397)\end{array}$ & $P$ Value & $\begin{array}{c}\text { Generic } \\
\text { Alternative } \\
(\mathrm{n}=541)\end{array}$ & $\begin{array}{c}\text { Abuse } \\
\text { Deterrent } \\
(\mathrm{n}=397)\end{array}$ & $P$ Value \\
\hline \multicolumn{10}{|c|}{ Charlson Comorbidity Index score } \\
\hline 0 (reference) & $9.38 \quad(0.14)$ & $10.06 \quad(0.15)$ & $<0.01$ & - & - & & $(0.16)$ & $9.29 \quad(0.16)$ & $<0.01$ \\
\hline 1 & $9.78 \quad(0.15)$ & $10.17 \quad(0.15)$ & $<0.01$ & - & - & & $(0.16)$ & $9.35 \quad(0.16)$ & $<0.01$ \\
\hline 2 & $10.01 \quad(0.17)$ & $10.36 \quad(0.17)$ & 0.02 & - & - & & $(0.19)$ & $9.23 \quad(0.18)$ & $<0.01$ \\
\hline $3+$ & $10.24 \quad(0.16)$ & $10.52 \quad(0.17)$ & 0.03 & - & - & & $(0.17)$ & $9.49 \quad(0.18)$ & $<0.01$ \\
\hline \multicolumn{10}{|c|}{ Comorbidities of addiction } \\
\hline No (reference) & $9.76 \quad(0.15)$ & $(0.16)$ & $<0.01$ & $(0.26)$ & $9.33(0.28)$ & 0.02 & - & - & \\
\hline Yes & $9.94 \quad(0.14)$ & $(0.14)$ & $<0.01$ & $(0.25)$ & $9.27 \quad(0.25)$ & 0.20 & - & - & \\
\hline
\end{tabular}

between the 2 groups. The overwhelming number of individuals in each group experienced only 1 emergency department visit during the study period ( $86 \%$ and $87 \%$ ). Therefore, it appears that the use of medical services including emergency services was not impacted by use of ADTR products. If abuse or misuse was higher in the SDF product group, it did not result in additional medical expenditures or emergency department visits. The median prescription drug expenditures were significantly different between the ADTR and SDF users, and increased with higher Charlson Comorbidity Index score (Table 5). Opioid-based prescription products comprised a substantial part of prescription drug expenditures and were significantly different between groups (median costs $\$ 9,922$ ADTR vs $\$ 1,532$ SDF; $P<0.01$ ). The total number of opioidbased prescriptions was higher in the ADTR group $(P<0.01)$.

\section{Limitations}

This research is not without limitations. For example, the use of administrative claims data that were collected for purposes of payment and not for research means that study covariates were limited to what was available. Indeed, factors such as member employment, social supports, and networks, which may have influenced medication adherence or even potential for drug abuse and related health care expenditures, were not collected and thus not evaluated in this study. It is also possible that misclassification of disease severity and comorbidities might have occurred because of errors in billing and coding. However, because the study data were restricted to records between 2013 and 2014, a period during which various quality control processes were instituted at Oklahoma Health Care Authority to ensure accuracy of claims billings and coding, it is unlikely such errors could have had a substantial impact on study findings (i.e., if such errors were committed, they occurred at very low proportions and thus had minimal influence on study findings). Furthermore, it is possible that some prescriptions may have been purchased by the members but not processed through the Oklahoma Medicaid payment system, and therefore were not included in this study. Such missing data could have led to an underestimation of the actual costs associated with ADTR or SDF opioid use. Because the omission of such costs is likely not different between these 2 groups, the patterns in observed associations were likely not impacted substantially for 2-level covariates (e.g., comorbidities of addiction, yes or no). On the other hand, the impact of such omissions on the direction of measures of association (regression coefficients) involving covariates with more than 2 levels (e.g., Charlson Comorbidity Index score) may not be predictable.

The products included in the ADTR classification were both abuse-deterrent and tamper-resistant formulations. It is possible that inclusion of both categories in a single classification could have influenced the results, potentially reducing the positive impact of the abuse-deterrent products. Additionally, there was no accounting for duration of use of the ADTR products by the members. It is possible that changes that occurred over time might be seen if the data were reviewed in a longitudinal fashion.

It is possible that members who had a past history of abuse might have been prescribed ADTR products over SDFs to help address suspected drug abuse or misuse. Because members with a history of drug abuse (or suspected drug abuse) tend to have high rates of relapse, ${ }^{30}$ the high expenditures observed among ADTR users could be partly attributed to the inclusion of such members in this study. Although such relations have been demonstrated in previous research, ${ }^{2-5}$ our study findings show that among ADTR users, members with comorbidities of addiction (a correlate of potential drug abuse) had slightly lower overall prescription expenditures than members without comorbidities of addiction (Table 4). However, because this association was not statistically significant $(P=0.23)$, cautious interpretation of these results is warranted. Similar results 
were observed for total health care and medical expenditure outcome models (Table 5). This finding suggests that the potential impact of selection bias (possibly related to the higher number of previous drug abusers being assigned to the ADTR group than to the SDF group) is likely minimal. In fact, a reverse relation or hypothesis seems more plausible.

Finally, the reimbursement to pharmacies for the products included in this research did not take into account rebates that were provided to Oklahoma Medicaid from the pharmaceutical manufacturers. Rebates to Medicaid programs can range from $23 \%$ to $50 \%$ based on the length of time a product has been on the market. Rebate amounts were not known to the authors and were not included in this research. Actual rebates are not typically available when administrative claims databases are used. However, because this research compares products, some consideration is necessary. It is unlikely that inclusion of rebates would have changed the direction of the overall results, although the magnitude would be moderated. At best, rebates of $50 \%$ would potentially have reduced the median ADTR costs to approximately $\$ 4,961$, well above the median of $\$ 1,532$ for SDF (which in theory would also have some reductions if rebates were applied). Rebates affect the net amount paid by the payer, regardless of the payer type (commercial vs. government), and each sector should view these results with their unique situation in mind. Rebates would not have affected the results of the medical costs, which remained similar between groups.

\section{Conclusions}

The abuse and misuse of medically prescribed opioid products is a growing health epidemic. A variety of attempts have been made to reduce the potential for abuse and misuse of these products through programmatic limitations and most recently through the development of ADTR formulations. The objectives of this study were to examine whether there was an association between overall health care expenditures (total health care, medical, and prescription expenditures) and the use of ADTR versus SDF opioid formulations, and whether member characteristics influenced this association. The results of this study of Oklahoma Medicaid members indicate that total health care spending is significantly higher for those using ADTR formulations. The additional expenditures were not found to be associated with medical expenditures, but were related to significantly higher spending for prescription drugs and specifically for opioid-based prescription drugs.

The results of this study are not a referendum on the efficacy of abuse-deterrent formulations of opioid drug products. Clearly, these new products make it more difficult to abuse or misuse prescription opioid formulations. Abusers cannot simply crush these tablets and then snort or inject the opioid, as with non-abuse-deterrent formulations. Utilization of these patented brand-name products comes with a significant price tag compared with generic versions of the original non- abuse-deterrent formulations. The results of this Medicaid claims-based study indicate that not only is prescription drug spending impacted by the use of abuse-deterrent formulations, but also that overall total health care expenditures are greater compared with use of the generic original formulations, despite controlling for opioid dependence and the comorbidities of addiction. Additional research is needed to determine the comparative effectiveness of existing opioid prescription formulations while accounting for the reasons why some members are prescribed ADTR versus SDF prescriptions.

\section{Authors}

SHELLIE L. KEAST, PharmD, PhD, is Assistant Professor; ARTHUR OWORA, MPH, CPH, is Research Biostatistician; and KEVIN FARMER, PhD, is Professor, University of Oklahoma College of Pharmacy, Oklahoma City, Oklahoma. NANCY NESSER, PharmD, JD, is Pharmacy Director, Oklahoma Health Care Authority, Oklahoma City, Oklahoma.

AUTHOR CORRESPONDENCE: Shellie Keast, PharmD, PhD, Assistant Professor, ORI-4403, P.O. Box 26901, Oklahoma City, OK 73126-0901. Tel.: 405.271.8222; Fax: 405.271.6602;

E-mail: shellie-keast@ouhsc.edu.

\section{DISCLOSURES}

No outside funding supported this research. Nesser is employed by the Oklahoma Health Care Authority, and Keast is a contractual employee for the Oklahoma Health Care Authority. The authors declare no other conflicts of interest.

Study design was primarily contributed by Keast, along with Nesser and Farmer. Keast took the lead in data collection, while data interpretation was primarily performed by Owora, along with Keast and assisted by Nesser and Farmer. The manuscript was written and revised by all authors equally.

\section{REFERENCES}

1. Substance Abuse and Mental Health Services Administration. Results from the 2013 National Survey on Drug Use and Health: summary of national findings. NSDUH Series H-48, HHS Publication No. (SMA) 14-4863. Rockville MD: Substance Abuse and Mental Health Services Administration; 2014. Available at: http://www.samhsa.gov/data/sites/ default/files/NSDUHresultsPDFWHTML2013/Web/NSDUHresults2013.pdf. Accessed January 4, 2016.

2. White AG, Birnbaum HG, Mareva MN, et al. Direct costs of opioid abuse in an insured population in the United States. J Manag Care Pharm. 2005;11(6):469-79. Available at: http://www.jmcp.org/doi/abs/10.18553/ jmcp.2005.11.6.469.

3. McAdam-Marx C, Roland CL, Cleveland J, Oderda GM. Costs of opioid abuse and misuse determined from a Medicaid database. J Pain Palliat Care Pharmacother. 2010;24(1):5-18.

4. Spiller H, Lorenz DJ, Bailey EJ, Dart RC. Epidemiological trends in abuse and misuse of prescription opioids. J Addictive Dis. 2009;28(2):130-36.

5. Ghate SR, Haroutiunian S, Winslow R, McAdam-Marx C. Cost and comorbidities associated with opioid abuse in managed care and Medicaid patients in the United States: a comparison of two recently published studies. J Pain Palliat Care Pharmacother. 2010;24(3):251-58. 


\section{Evaluation of Abuse-Deterrent or Tamper-Resistant Opioid Formulations on Overall Health Care Expenditures in a State Medicaid Program}

6. Executive Office of the President of the United States of America. Epidemic: responding to America's prescription drug abuse crisis. 2011. Available at: https://www.whitehouse.gov/sites/default/files/ondcp/policyand-research/rx_abuse_plan.pdf. Accessed January 11, 2016.

7. U.S. Food and Drug Administration. Abuse-deterrent opioids-evaluation and labeling. Guidance for industry. April 2015. Available at: http://www. fda.gov/downloads/Drugs/GuidanceComplianceRegulatoryInformation/ Guidances/UCM334743.pdf. Accessed December 28, 2015.

8. Oxycontin - oxycodone hydrochloride tablet, film coated, extended release. Purdue Pharma LP. Revised August 2015. Available at: http://app.purduepharma.com/xmlpublishing/pi.aspx?id=o. Accessed December 28, 2015.

9. Embeda-morphine sulfate and naltrexone hydrochloride capsule, extended release. Pfizer Laboratories. Revised October 2014. Available at: http://labeling pfizer.com/ShowLabeling.aspx?id=694. Accessed December 28, 2015.

10. Hysingla ER - hydrocodone bitartrate tablet, extended release. Purdue Pharma LP. Revised February 2015. Available at: http://app.purduepharma com/xmlpublishing/pi.aspx?id=h. Accessed December 28, 2015.

11. FDA approves Exalgo $32 \mathrm{mg}$. Drugs.com. August 27, 2012. Available at: http://www.drugs.com/newdrugs/fda-approves-mallinckrodt-s-exalgohydromorphone-hcl-extended-release-32-mg-cii-opioid-tolerant-3453.html. Accessed December 28, 2015

12. U.S. Food and Drug Administration. Timeline of selected FDA activities and significant events addressing opioid misuse and abuse. Last updated November 18, 2015. Available at: http://www.fda.gov/Drugs/DrugSafety/ InformationbyDrugClass/ucm338566.htm. Accessed December 28, 2015

13. Zohydro ER (hydrocodone bitartrate) extended-release capsules, for oral use, CII. Pernix Therapeutics, LLC. May 2015. Available at: http://www. zohydroer.com/downloads/ZOHYDROERFullPrescribingInformation.pdf. Accessed December 28, 2015

14. Rossiter LF, Kirson NY, Shei A, et al. Medical cost savings associated with an extended-release opioid with abuse-deterrent technology in the U.S. J Med Econ. 2014;17(4):279-87.

15. Cicero TJ, Ellis MS. Abuse-deterrent formulations and the prescription opioid abuse epidemic in the United States: lessons learned from OxyContin. JAMA Psychiatry. 2015;72(5):424-30

16. Havens JR, Leukefeld CG, DeVeaugh-Geiss AM, Coplan P, Chilcoat HD. The impact of a reformulation of extended-release oxycodone designed to deter abuse in a sample of prescription opioid abusers. Drug Alcohol Depend. 2014;139:9-17.

17. Cassidy TA, DasMahapatra P, Black RA, Wieman MS, Butler SF. Changes in prevalence of prescription opioid abuse after introduction of an abusedeterrent opioid formulation. Pain Med. 2014;15(3):440-51.
18. Sessler NE, Downing JM, Kale H, Chilcoat HD, Baumgartner TF, Coplan PM. Reductions in reported deaths following the introduction of extended-release oxycodone (OxyContin) with an abuse-deterrent formulation. Pharmacoepidemiol Drug Saf. 2014;23(12):1238-46.

19. Hwang CS, Chang HY, Alexander GC. Impact of abuse-deterrent OxyContin on prescription opioid utilization. Pharmacoepidemiol Drug Saf. 2015;24(2):197-204.

20. Severtson SG, Bartelson BB, Davis JM, et al. Reduced abuse, therapeutic errors, and diversion following reformulation of extended-release oxycodone in 2010. J Pain. 2013;14(10):1122-30.

21. Butler SF, Cassidy TA, Chilcoat $\mathrm{H}$, et al. Abuse rates and routes of administration of reformulated extended-release oxycodone: initial findings from a sentinel surveillance sample of individuals assessed for substance abuse treatment. J Pain. 2013;14(4):351-58.

22. Coplan PM, Kale H, Sandstrom L, Landau C, Chilcoat HD. Changes in oxycodone and heroin exposures in the National Poison Data System after introduction of extended-release oxycodone with abuse-deterrent characteristics. Pharmacoepidemiol Drug Saf. 2013;22(12):1274-82.

23. Winegarden W. Estimating the net economic benefit of abuse-deterrent opioids. Issue Brief. EconoSTATS at George Mason University. March 2015. Available at: http://econostats.org/estimating-the-net-economic-benefit-ofabuse-deterrent-opioids/. Accessed December 30, 2015.

24. Keast SL, Nesser N, Farmer K. Strategies aimed at controlling misuse and abuse of opioid prescription medications in a state Medicaid program: a policymaker's perspective. Am J Drug Alcohol Abuse. 2015;41(1):1-6.

25. Caetano PA, Lam JM, Morgan SG. Toward a standard definition and measurement of persistence with drug therapy: examples from research on statin and antihypertensive utilization. Clin Ther. 2006;28(9):1411-24.

26. Hudson M, Rahme E, Richard H, Pilote L. Comparison of measures of medication persistency using a prescription drug database. Am Heart J. 2007;153(1):59-65.

27. Andersen R, Newman JF. Societal and individual determinants of medical care utilization in the United States. Milbank Q. 2005;83(4). Online only. Available at: http://www.ncbi.nlm.nih.gov/pmc/articles/PMC2690261/. Accessed January 11, 2016.

28. Charlson M, Szatrowski TP, Peterson J, Gold J. Validation of a combined comorbidity index. J Clin Epidemiol. 1994;47(11):1245-51.

29. Quan H, Li B, Couris CM, et al. Updating and validating the Charlson comorbidity index and score for risk adjustment in hospital discharge abstracts using data from 6 countries. Am J Epidemiol. 2011;173(6):676-82.

30. McLellan AT, Lewis DC, O'Brien CP, Kleber HD. Drug dependence, a chronic medical illness: implications for treatment, insurance, and outcomes evaluation. JAMA. 2000;284(13):1689-95 
Evaluation of Abuse-Deterrent or Tamper-Resistant Opioid Formulations

on Overall Health Care Expenditures in a State Medicaid Program

\section{APPENDIX Comorbidities Associated with Addiction ${ }^{2,5}$}

\begin{tabular}{|c|c|c|}
\hline Grouping & Included Diagnoses & ICD-9-CM Code \\
\hline $\begin{array}{l}\text { Substance abuse } \\
\text { (excluding opioid or sedative) }\end{array}$ & $\begin{array}{l}\text { Alcohol dependence syndrome, drug depen- } \\
\text { dence, nondependent abuse of drugs, can- } \\
\text { nabis, tobacco, etc. }\end{array}$ & $\begin{array}{l}\text { 303.xx, 304.1x-304.6x, 304.8x, 304.9x, 305.0x-305.4x, } \\
\text { 305.6x-305.9x, V11.3 }\end{array}$ \\
\hline HIV/AIDS & NA & 042.xx, 079.53, v08.xx, 795.71 \\
\hline Hepatitis (A, B, and C) & NA & $\begin{array}{l}070.0 \mathrm{x}, 070.1 \mathrm{x}, 070.2 \mathrm{x}, 070.3 \mathrm{x}, 070.41,070.44,070.51,070,54 \\
070.70,070.71, \mathrm{~V} 02.61, \mathrm{~V} 02.62\end{array}$ \\
\hline Skin infections & $\begin{array}{l}\text { Cellulitis due to drugs and medicines, } \\
\text { chronic ulcer, etc. }\end{array}$ & $\begin{array}{l}\text { 111.8x, 111.9x, 680.xx, 681.xx, 682.xx, 684.xx, 685.xx, 686.xx, } \\
\text { 681.xx, 693.0x, 693.8x, 693.9x, 707.9x }\end{array}$ \\
\hline Mental health & $\begin{array}{l}\text { Organic psychotic conditions, other } \\
\text { psychoses, neurotic disorders, personality } \\
\text { disorders, nonpsychotic disorders, } \\
\text { intellectual disabilities, etc. }\end{array}$ & $\begin{array}{l}\text { 290.xx, 291.xx, 292.xx, 293.xx, 294.xx, 295.xx, 296.xx, 297.xx, } \\
\text { 298.xx, 299.xx, 300.xx, 301.xx, 302.xx, 306.xx, 307.xx, 308.xx, } \\
\text { 309.xx, 310.xx, 311.xx, 312.xx, 313.xx, 314.xx, 315.xx, 316.xx, } \\
\text { 317.xx, 318.xx, 319.xx, V11.0x, V11.1x, V11.2x, V11.4x, V11.8x, } \\
\text { V11.9x }\end{array}$ \\
\hline Liver disease & $\begin{array}{l}\text { Necrosis of liver, cirrhosis, chronic liver } \\
\text { disease, etc. }\end{array}$ & $\begin{array}{l}\text { 570.xx, 571.0x, 571.2x, 571.3x, 571.4x, 571.5x, 571.6x, 571.8x, } \\
\text { 571.9x, 572.xx, 573.xx }\end{array}$ \\
\hline Pancreatitis & NA & $577 . \mathrm{xx}$ \\
\hline Motor vehicle accidents & NA & $\begin{array}{l}\text { E810.xx, E811.xx, E812.xx, E813.xx, E814.xx, E815.xx, E816.xx, } \\
\text { E817.xx, E818.xx, E819.xx }\end{array}$ \\
\hline Gastrointestinal bleeding & $\begin{array}{l}\text { Gastrointestinal hemorrhage, gastric ulcer, } \\
\text { duodenal ulcer, peptic ulcer, gastrojejunal } \\
\text { ulcer, esophageal varices, etc. }\end{array}$ & $\begin{array}{l}\text { 578.xx, 456.xx, 530.8x, 531.0x, 531.2x, 532.0x, 532.2x, 533.0x, } \\
533.2 x, 534.0 x, 534.2 x\end{array}$ \\
\hline Sexually transmitted diseases & $\begin{array}{l}\text { Syphilis, candidiasis, chlamydia, genital } \\
\text { warts, gonorrhea, trichomoniasis, dysplasia } \\
\text { of cervix or vagina, etc. }\end{array}$ & $\begin{array}{l}\text { 090.xx, 091.xx, 092.xx, 093.xx, 094.xx, 099.xx, 112.1x, 112.2x, } \\
\text { 483.1x, 078.19, 078.11, V02.7x, V02.8x, 647.0x, 647.1x, 647.2x, } \\
\text { 614.xx, 615.xx, 616.xx, 131.00, 131.01, 131.02, 131.03, 131.09, } \\
\text { 622.1x, 623.0x }\end{array}$ \\
\hline Burns & NA & $\begin{array}{l}\text { 940.xx, 941.xx, 942.xx, 943.xx, 944.xx, 945.xx, 946.xx, 947.xx, } \\
\text { 948.xx, 949.xx }\end{array}$ \\
\hline $\begin{array}{l}\text { Trauma (excluding motor } \\
\text { vehicle accidents) }\end{array}$ & $\begin{array}{l}\text { Fractures, dislocation, open wounds, contu- } \\
\text { sions, sprains and strains, etc. }\end{array}$ & $\begin{array}{l}\text { 800.xx-848.xx, 850.xx-854.xx, 860.xx-887.xx, 890.xx-897.xx, } \\
\text { 900.xx-939.xx, 950.xx-959.xx }\end{array}$ \\
\hline Poisonings (excluding opioid abuse) & NA & $\begin{array}{l}\text { 960.xx, 961.xx, 962.xx, 963.xx, 964.xx, 965.00, 965.01, 965.03, } \\
\text { 965.04, 965.05, 965.07, 965.08, 966.xx, 967.xx, 968.xx, 969.xx, } \\
\text { 970.xx-979.xx, 980.xx-989.xx }\end{array}$ \\
\hline
\end{tabular}

AIDS = acquired immunodeficiency syndrome; HIV=human immunodeficiency virus; ICD-9-CM = International Classification of Diseases, Ninth Revision, Clinical Modification; NA = not applicable. 